\title{
Mastitis in Small Ruminants ${ }^{1}$
}

\author{
Izabella Toledo and Justina Dacey ${ }^{2}$
}

Mastitis, one of the most common health problems affecting sheep and goats, often reduces animal performance and productivity as well as farm profitability. The purpose of this article is to help small ruminant producers to identify, treat, control and prevent mastitis in small ruminants.

\section{What is mastitis?}

Mastitis is an inflammation or infection of the mammary gland, or udder, that may occur in sheep, goats, cows or any other milk-producing animal. It is caused by different factors such as stress, physical injury, or bacteria. Risk factors include udder and teat shape, improper milking procedures, high milk production, raising multiple lambs or kids, or wet, dirty, or crowded conditions.

Most cases of mastitis occur during the first weeks after lambing or kidding or immediately before weaning. The most common strains that may cause mastitis in small ruminants are Streptococcus sp., Staphylococcus sp., Pasteurella sp., and coliforms, such as E. coli. The exact type of bacteria causing the mastitis can only be determined by laboratory analysis. Various pathogens may cause either contagious or environmental mastitis. Contagious infections are associated with transmission between animals or even from human-animal interactions, while environmental mastitis is directly related to the cleanliness of the environment where the animals are kept.

\section{Types and Symptoms of Mastitis}

There are two types of mastitis: clinical or subclinical. Clinical mastitis can be either chronic or acute and involves physical changes in the udder. The udder usually becomes swollen and warm, and sometimes painful to the touch. Ewes and does affected with clinical mastitis may develop a fever $\left(105-107^{\circ} \mathrm{F}\right)$, go off feed, become depressed, and often require supportive care. Additionally, they may hold their rear foot up, as if they are lame, and refuse to allow their lambs or kids to nurse. As a result, lambs and kids may die from lack of milk or a bacterial infection from infected milk.

Milk of ewes and does affected by clinical mastitis may be watery, smelly, and discolored, and contain clots or flakes. In severe cases, blood supply to the udder is affected, possibly resulting in a blue discoloration of the udder.

Subclinical mastitis is more common and difficult to identify than clinical mastitis. It is only detectable by using the California Mastitis Test (CMT), by measuring the number of somatic cells (i.e., inflammatory cells) in the milk, or by culturing milk in the laboratory. In case of a positive CMT, additional laboratory tests are recommended to determine the type of organisms causing the infection.

In some cases of subclinical mastitis, the udder may be firm and hot. Lambs or kids of affected ewes or does may have poor growth rates with occasional deaths. Usually, ewes and does with subclinical mastitis appear healthy, but decreases

1. This document is AN367, one of a series of the Department of Animal Sciences, UF/IFAS Extension. Original publication date September 2021. Visit the EDIS website at https://edis.ifas.ufl.edu for the currently supported version of this publication.

2. Izabella Toledo, regional specialized Extension agent II, dairy, UF/IFAS Extension Northeast District; and Justina Dacey, Extension agent, natural resources and agriculture, UF/IFAS Extension Nassau County; UF/IFAS Extension, Gainesville, FL 32611.

The Institute of Food and Agricultural Sciences (IFAS) is an Equal Opportunity Institution authorized to provide research, educational information and other services

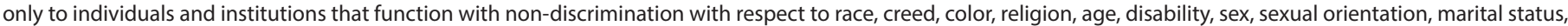

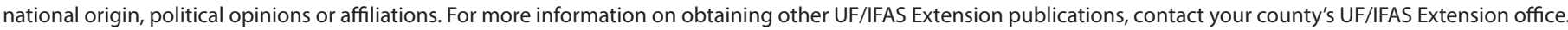
U.S. Department of Agriculture, UF/IFAS Extension Service, University of Florida, IFAS, Florida A \& M University Cooperative Extension Program, and Boards of County Commissioners Cooperating. Nick T. Place, dean for UF/IFAS Extension. 
in milk production and development of lumps (i.e., scar tissue) in their udders may occur. Compromisedhealth, inadequate facilities, and insufficient nutritional management may trigger the progression from subclinical to clinical mastitis.

\section{Mastitis Treatment}

Treatments vary depending on the case; however, mastitis is generally treated with either injectable or intramammary antibiotics. A veterinarian can diagnose the condition and identify the infectious pathogen as well as the proper treatment. Because there are no antibiotics that are labeled for use in small ruminants for the treatment of mastitis, all treatment of intramammary infections is considered extra-label and must be done through a veterinarian.

A dry period (i.e., 60 days before parturition) is recommended to allow the mammary systems to recuperate and prepare for the next lactation. Intramammary dry-off treatment may help with treatment and/or prevention of mastitis during the dry period. This treatment also must be done under the direction of a veterinarian because there are no dry-off treatment antibiotics labeled for small ruminants.

When using antibiotic therapy, it is very important for producers to follow drug withdrawal intervals to prevent contaminated meat and/or milk from entering the food chain.

\section{Mastitis Costs}

Mastitis is one of the most costly diseases of small ruminants. Direct costs include decreases in milk production and lower concentrations of milk components, early cooling and replacement costs, treatment costs, and increases in management costs. The greatest indirect cost comes from premature culling and replacement loss.

\section{Mastitis Prevention}

Mastitis can be prevented with good management and sanitation. Clean housing and proper milking practices are the key to the prevention of mastitis in small ruminants. The risk of mastitis increases greatly in dirty environments. When dairy goats lie down, their udders are in direct contact with the floor; thus, bedding as well as living and birthing areas should be clean and dry at all times. There should be good drainage around the housing and lots to help eliminate muddy areas. Additionally, animals should not be overcrowded, and milking procedures should be followed properly and consistently. Milking clean, dry, and properly stimulated teats allows the most efficient harvesting of milk and reduces the risk of udder infections. These management measures help reduce the chances of an animal coming into contact with harmful bacteria, especially animals that have a higher risk of becoming contaminated (e.g., those in early or late lactation and those that sustain any type of physical injury to the udder). Moreover, good ewe and doe nutritional management and maintenance of the health of ewes, does, lambs, and kids can also aid in the prevention of mastitis.

Preventing respiratory disease in lambs and kids also contributes to mastitis prevention. Pasteurella haemolytica, the bacteria that causes baby lamb and kid pneumonia, is a major cause of mastitis in ewes and does. Sore mouth is another contributing factor because lambs or kids with mouth lesions can infect their dams and any other ewe or doe that may nurse them.

Use of good management practices and quick action if mastitis is discovered will help keep this particular health issue to a minimum. Ewes and does that show signs of mastitis should be separated from the rest of the herd and treated accordingly. Contaminated milk should be discarded. Lambs or kids of contaminated ewes or does should be bottle fed.

Weaning lambs or kids from ewes or does whose milk production has not declined sufficiently puts severe stress on the udder; therefore, proper management at weaning is also necessary to prevent mastitis. Restriction of feed and water of ewes and does for 1 to 2 days after weaning will contribute to a rapid decrease in milk production. Another alternative to lessen the occurrence of mastitis is to delay weaning until after milk production has decreased sufficiently. The udders of all ewes and does in the herd should always be examined after weaning and before breeding. It is recommended that ewes and does with hard lumps in the udders or permanent damage to one or more teats should be culled, because these ewes and does will become increasingly poor producers of milk. Additionally, producers should consider culling ewes and does with severe mastitis that do not show an immediate response to treatment.

\section{Summary}

Mastitis is a complicated and costly disease. Good housing hygiene practices and consistent milking procedures are crucial to control and minimize its negative impact. Proper diagnosis, treatment, and replacement of chronically infected animals contribute to the reduction of the detrimental effects of mastitis in small ruminants. 